\title{
Dorsoventral Polarity and Mesentoblast Determination as Concomitant Results of Cellular Interactions in the Mollusk Patella vulgata
}

\author{
J. A. M. VAN DEN BiggelaAR* AND P. Guerrier $\dagger$ \\ *Zoological Laboratory, Padualaan 8, Utrecht, the Netherlands, and + Station Biologique, \\ 29.211 Roscoff, France
}

Received June 27, 1977; accepted in revised form September 7, 1978

\begin{abstract}
In mollusks with an equal four-cell stage, dorsoventral polarity becomes noticeable in the interval between the formation of the third and fourth quartet of micromeres, i.e., between the fifth and sixth cleavage. One of the two macromeres at the vegetal cross-furrow then partly withdraws from the surface and becomes located more toward the center of the embryonic cell mass than the other three macromeres. Only this specific macromere (3D) contacts the micromeres of the animal pole, divides with a delay, and develops into the stem cell of the mesentoblast (4d). After suppression of the normal contacts between micromeres and macromeres either by dissociation of the embryos or by deletion of first quartet cells, the normal differentiation of the macromeres fails to appear. By deleting a decreasing number of first quartet cells, an increasing percentage of embryos shows the normal differentiation pattern. Deletion of one of the crossfurrow macromeres does not preclude formation of the mesentoblast, which then originates by differentiation of an other macromere. It is concluded that initially the embryo is radially symmetrical and that the four quadrants have identical developmental capacities; mesentoblast differentiation from one macromere is induced through the contacts of the first quartet cells and that single macromere.
\end{abstract}

\section{INTRODUCTION}

In mollusks, only one of the four vegetal macromeres contributes to the formation of the mesoderm. In species with an equal four-cell stage, this macromere can be recognized after the fifth cleavage when it gradually attains a central position in the embryo, and at the sixth cleavage by the formation of the mesentoblast $4 \mathrm{~d}$.

A detailed cytological analysis of the way in which one of the four macromeres acquires a central position and develops into the mesentoblast mother cell has been made in Lymnaea stagnalis (van den Biggelaar, 1976a,b), Patella vulgata (van den Biggelaar, 1977), and Haliotis tuberculata (in preparation). These descriptive studies only permit us to speculate about the mechanisms that force one of the four macromeres into a central position in the embryo, where it makes contact with the inner cell walls of most of the other blastomeres and finally forms the mesentoblast.
The differentiation of the macromeres in Patella has been explained in a general way by assuming a differential cellular adhesiveness (van den Biggelaar, 1977). This means that the final disposition, in which the animal micromeres are in touch with one of the four macromeres (3D), is the only stable configurational equilibrium that can be attaincd under the influence of different ad hesive strengths and surface tensions.

According to the above concept all four macromeres are equipotential, and each may have the same developmental potential to behave as 3D if it is directed into a central position and develops exclusive contacts with the micromeres.

From cell lineage studies it is known that usually one of the two macromeres at the vegetal cross-furrow forms the mesentoblast. If this macromere is indeed determined by an essentially arbitrary but inevitable choice made up by the animal first quartet cells (van den Biggelaar, 1976a), it 
may be assumed that the mesentoblast develops from an other macromere after removal of one of these cross-furrow macromeres. In Patella, the mesentoblast-forming macromere may be distinguished from the other macromeres by its central position, by a division delay of about $20 \mathrm{~min}$, and by an unequal division (van den Biggelaar, 1977). Moreover, if the micromeres play a cardinal role in the differentiation of the macromeres, deletion of an increasing number of animal micromeres may interfere with the determination of the macromere that develops the mesentoblast. Deletion of the whole first quartet of micromeres may completely prevent the formation of a central cell and of division asynchrony. The results of these two kinds of deletion experiments appear to confirm the proposed hypothesis.

\section{MATERIALS AND METHODS}

Patella vulgata is common in the Roscoff area. The animals were collected once or twice a week from October to the end of January. After dissection each gonad was vigorously moved around in a Boveri dish with seawater. Next, the eggs were fertilized. At the onset of first cleavage, normal two-cell stages were collected one by one, which then were allowed to develop at about $18^{\circ} \mathrm{C}$ until reaching the required stage.

The embryos were dissociated by treating them briefly $(30-120 \mathrm{sec})$ with an isosmotic solution of $0.495 \mathrm{M} \mathrm{KCl}, 0.035 \mathrm{M}$ sodium citrate, $0.5 \mathrm{~m} M$ EDTA, adjusted to pH 8 with $\mathrm{NaOH}$ (Krischner and Chambers, 1970). Deletion experiments were performed with a fine breaking-pipet. The opening was placed upon the blastomere to be removed, which then was carefully suctioned by mouth into the pipet. At first the cell membrane resists the suction and enteres only slightly into the capillary; progressive suction causes the membrane to burst. Usually, the remnants of the killed blastomere are not actively removed, but are thrown off by the embryo. The devel- opment of the individual embryos has been studied microscopically. The embryos were placed upside-down, with the vegetal pole facing the observer. A ring of paraffin oil is put around the drop of seawater containing the embryos, but a free space is left in between. The preparation is covered with a coverglass without changing the orientation of the embryos. In this way the development can be observed for several hours at a magnification of $400 \times$.

\section{RESULTS}

\section{Division Chronology of the Macromeres} at the Formation of the Fourth Quartet of Micromeres after Deletion of One of the Vegetal Cross-furrow Macromeres

One of the cross-furrow macromeres was removed within $10 \mathrm{~min}$ after the onset of the 32-cell stage (Figs. 1, 4, and 11a). The division chronology and the formation of a mesentoblast have been followed in 13 control and 24 deleted embryos. In the control embryos, the average division delay of $3 \mathrm{D}$ was $17.2 \pm 6.6 \mathrm{~min}$ as compared to $3 \mathrm{~A}, 3 \mathrm{~B}$, and $3 \mathrm{C}$ (Fig. 2). In 19 embryos with a deleted macromere $(79 \%)$, the remaining cross-furrow macromere (3B/3D) has a division delay of the same order $(16.3 \pm 5.1$ min; Fig. 5) as in control embryos. In 10 of these 19 embryos the course of development has been traced up to the first division of the mesentoblast ( $4 \mathrm{~d}$ or $\mathrm{M}$ ). In each of these 10 embryos the division of the mesentoblast $\mathrm{M}$ into $\mathrm{M} 1$ and M2 could be observed. In three other embryos one of the lateral macromeres $(3 \mathrm{~A} / 3 \mathrm{C})$ intruded the farthest and divided with a delay of the same order as that of $3 \mathrm{D}$ in control embryos. The micromere that developed from this lateral macromere divided as a normal $\mathrm{M}$-cell. In the remaining two embryos none of the macromeres attained a central position, and the fourth quartet cells were formed almost synchronously; no M-cell was formed.

The central position of one macromere necessarily involves a reorientation of the other blastomeres. As a result, the initial 
radial configuration of the cells changes into a bilateral symmetrical pattern. This becomes particularly evident about $25 \mathrm{~min}$ before the division of the macromeres $3 \mathrm{~A}$, $3 \mathrm{~B}$, and $3 \mathrm{C}$ of normal embryos, when the third quartet cells $3 \mathrm{a}-3 \mathrm{~d}$ begin to divide. Next to the central position of $3 \mathrm{D}$, this division forms an additional landmark for the plane of bilateral symmetry and for dorsoventral polarity of the embryo. The dorsal micromeres ( $3 c$ and $3 \mathrm{~d}$ ) divide into small vegetal $\left(3 c^{2}\right.$ and $3 d^{2}$, closely located to $3 \mathrm{D})$, and larger upper cells $\left(3 \mathrm{c}^{1}\right.$ and $\left.3 \mathrm{~d}^{1}\right)$. In the ventral micromeres $3 \mathrm{a}$ and $3 \mathrm{~b}$, the division inequality is reversed. The higher cells $3 a^{1}$ and $3 b^{1}$ are the smaller and $3 a^{2}$ and $3 b^{2}$ are the larger daughter cells (Fig. 2). In none of the embryos with a deleted macromere did this differentiation appear to be independent of the central and delayed macromere. Whether it was the remaining cross-furrow or one of the lateral macromeres which formed the mesentoblast and behaved as $3 \mathrm{D}$, the size differences in the division of the third quartet cells proved to be related to that central and delayed macromere (Fig. 5). Consequently, if a noncross-furrow macromere develops into the mesentoblast mother cell, the adjacent third quartet cells to the right and to the left must represent the dorsal micromeres, and the opposite two third quartet cells must represent the ventral micromeres.

In one out of a great number of control embryos, it was observed that one of the lateral macromeres had attained the axial position. Also in this embryo, the deviation of radial symmetry in the third quartet cells proved to be correlated with the central macromere and not with one of the crossfurrow macromeres.

\section{Division Chronology of the Macro- meres after Dissociation of the Embryos at the 16- or Early 32-Cell Stage}

A possible interaction between the macromeres and the micromeres can be inhibited by dissociating the blastomeres with citrated seawater. Dissociation was usually performed at the eight-cell stage. After further division, the daughter cells of each blastomere stayed together (Figs. 8, 9, and 10). The course of cleavage of the separated blastomeres continued in step with that of the controls up to the 32-cell stage. In embryos dissociated at the onset of the 32-cell stage, it has often been observed that the derivatives of the same quadrant maintain their contacts, whereas the individual quadrants are separated from each other, except at the vegetal pole or except at both poles of the egg axis. In these embryos the original cross-furrow macromeres can be recognized (Figs. 6 and 7). In other embryos, the interquadrant junctions at the cross-furrows have also disappeared. In both types of embryos the divisions of the macromeres could be followed accurately.

FIG. 1. Vegetal view of an embryo at the beginning of the 32-cell stage. The animal cross-furrow at the opposite pole and the cross-furrow between $3 \mathrm{~B}$ and $3 \mathrm{D}$ are the only deviations of radial symmetry.

FIG. 2. Vegetal view of an embryo at the end of the sixth cleavage. Note the division delay of 3D compared to $3 \mathrm{~A}, 3 \mathrm{~B}$, and $3 \mathrm{C}$. In addition to this division asynchrony, the dorsoventral polarity is adumbrated by the division inequality in the third quartet of micromeres. In the ventral quadrants the micromeres $3 \mathrm{a}^{1}$ and $3 \mathrm{~b}^{1}$ are small, the dorsal counter parts $3 c^{1}$ and $3 d^{1}$ are large; the ventral micromeres $3 a^{2}$ and $3 b^{2}$ are large, and the equivalent dorsal micromeres $3 \mathrm{c}^{2}$ and $3 \mathrm{~d}^{2}$ are small.

FIG. 3. Ventral view of an embryo with a deletion of the first quartet of micromeres. End of sixth cleavage. 3A-3D divide synchronously. The third quartet cells fail to develop the normal size differences.

FIG. 4. Vegetal view of an embryo shortly after fifth cleavage, after deletion of a cross-furrow macromere.

FIG. 5. Micrograph of an embryo with a cross-furrow macromere deletion at the end of sixth cleavage. Vegetal view. The quadrant of the remaining cross-furrow macromere develops into the dorsal quadrant. Note the presence of normal size differences in the third quartet of micromeres: $3 c^{2}$ and $3 \mathrm{~d}^{2}$ are small, and $3 \mathrm{a}^{2}$ and $3 \mathrm{~b}^{2}$ are large. cf. Figs. 2 and 3.

Fig. 6. Partly dissociated embryo. The four quadrants still adhere at the vegetal pole. The cross-furrow has been indicated. 

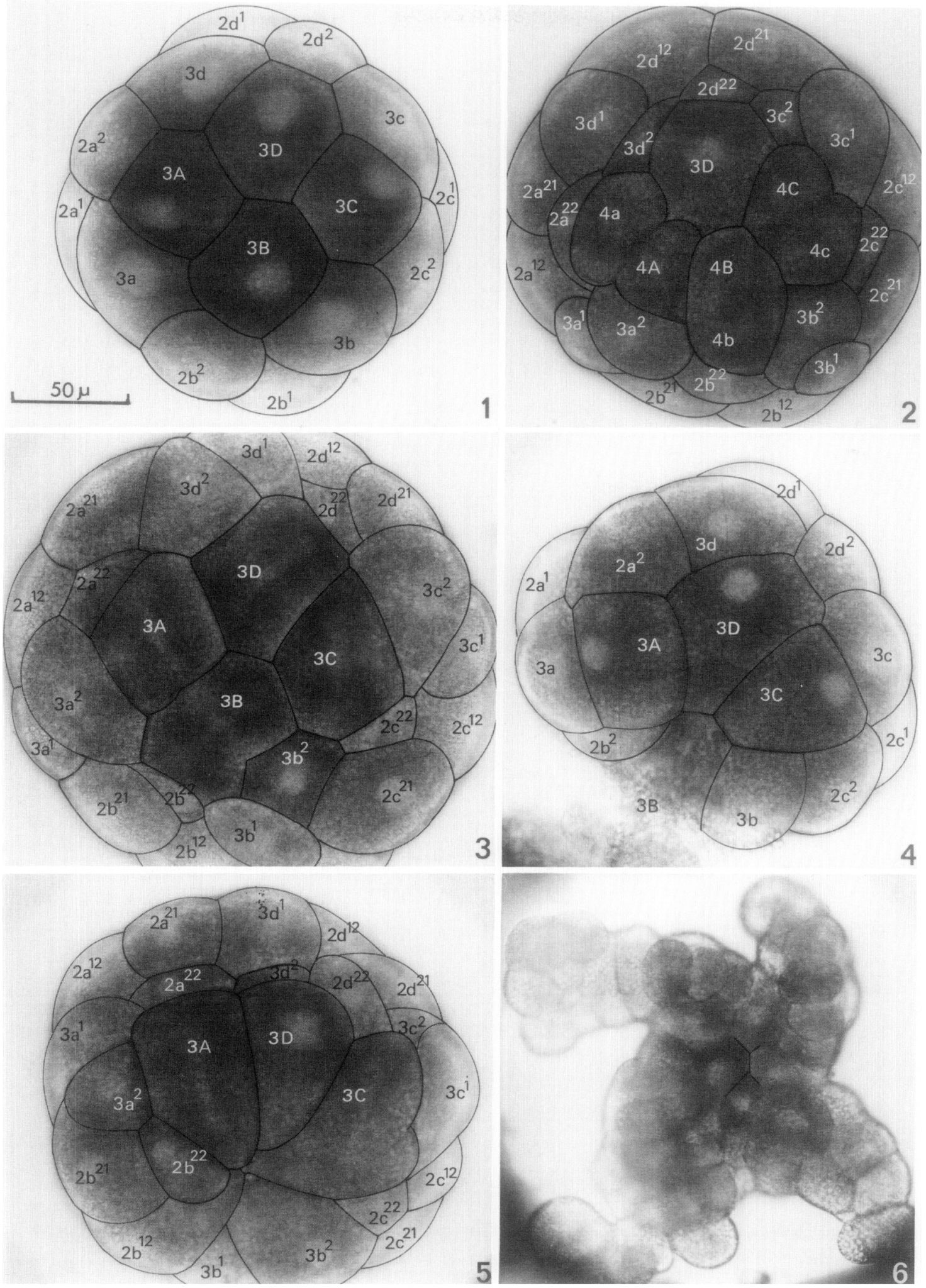

Figs. 1-6 


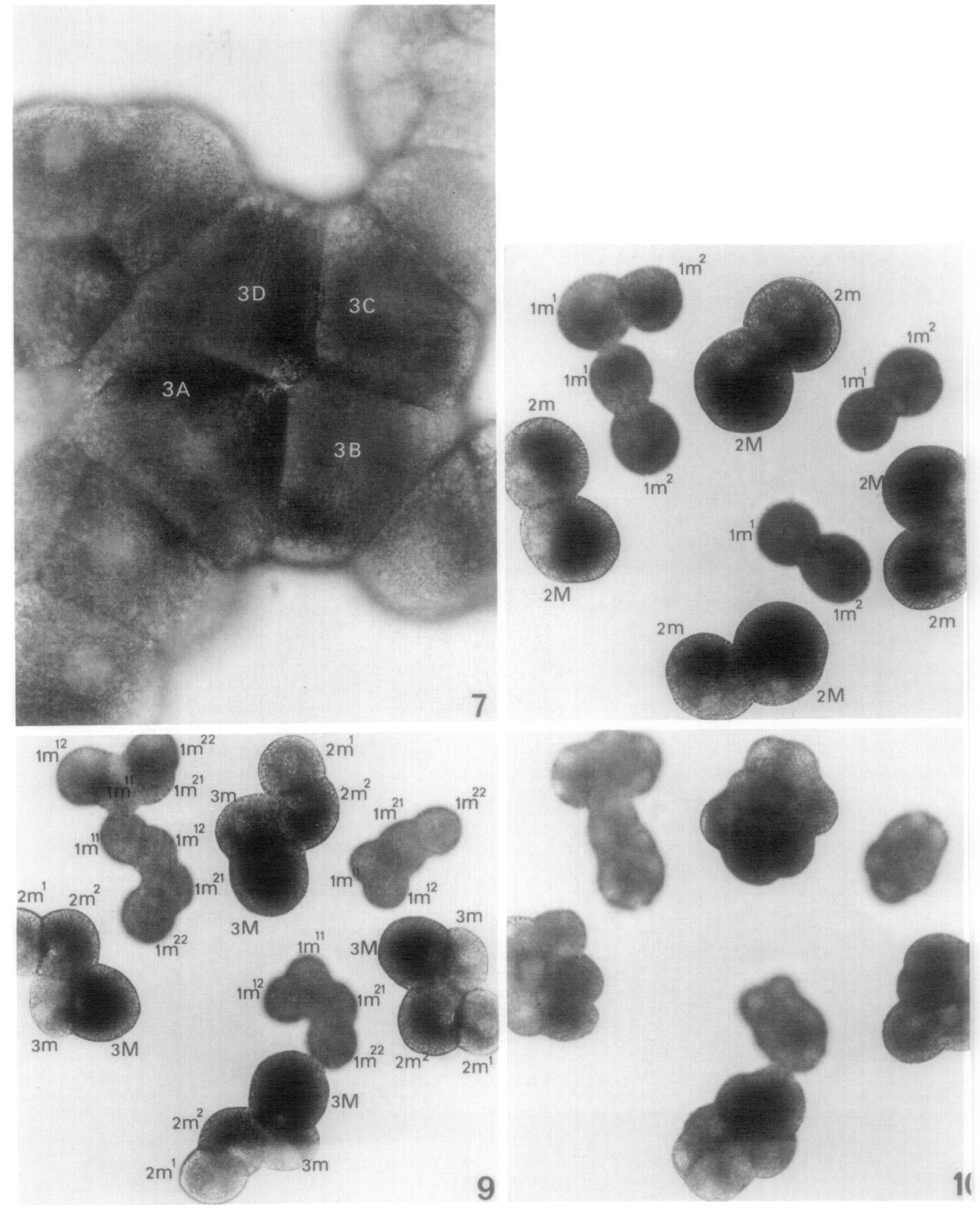

FIG. 7. Partly dissociated embryo with preserved contacts between the macromeres that divide synchronously.

Fig. 8. Embryo dissociated at the eight-cell stage showing the formation of the second quartet of micromeres and the first division of the first quartet cells.

Fig. 9. Same embryo as shown in Fig. 8 after formation of the third quartet of micromeres. The second quartet cells have divided once, and the first quartet cells have divided twice.

Fig. 10. Same embryo as shown in Figs. 8 and 9 after another cleavage. Now the cells have formed compact groups in which it was no longer possible to denominate the individual blastomeres. 
The division chronology of the micromeres can only be presented with some reservations. In dissociated and control embryos an exactly comparable interval of mitotic inactivity was noticed after the formation of the third quartet of micromeres. During this period of about $90 \mathrm{~min}$ the mutual affinity of the blastomeres seemed to increase, as the partly dissociated cells started to form more closed and compact cell masses (Fig. 10). During normal development the first cells to resume mitotic activity after fifth cleavage are the primary trochoblasts, the two lowest tiers of first quartet cells, $1 \mathrm{a}^{21}-1 \mathrm{~d}^{21}$ and $1 \mathrm{a}^{22}-1 \mathrm{~d}^{22}$. About 5 to 10 min later, the animal tier $1 \mathrm{a}^{11}-1 \mathrm{~d}^{11}$ divides almost in unison with the two tiers of second quartet cells, $2 \mathrm{a}^{1}-2 \mathrm{~d}^{1}$ and $2 \mathrm{a}^{2}-2 \mathrm{~d}^{2}$. Another 5 to $10 \mathrm{~min}$ later the micromeres $1 \mathrm{a}^{12}-1 \mathrm{~d}^{12}$ and $3 \mathrm{a}-3 \mathrm{~d}$ resume division, followed 25 min later by the macromeres $3 \mathrm{~A}$, $3 \mathrm{~B}$, and $3 \mathrm{C}$, and then with an additional delay of about $20 \mathrm{~min}$, by macromere $3 \mathrm{D}$ (van den Biggelaar, 1977).

The cleavage schedule of dissociated embryos reflects the normal timetable up to the 32-cell stage, but it begins to deviate at the transition to the 64-cell stage. All four tiers of micromeres of the first quartet, $1 \mathrm{a}^{11}-1 \mathrm{~d}^{11}, 1 \mathrm{a}^{12}-1 \mathrm{~d}^{12}, 1 \mathrm{a}^{21}-1 \mathrm{~d}^{21}$, and $1 \mathrm{a}^{22}-1 \mathrm{~d}^{22}$, simultaneously resumed cleavage about 14 min earlier than the micromeres of the second quartet. Another 6 min later the third quartet cells 3a-3d divided, followed almost immediately by the four macromeres. In embryos with completely separated quadrants, as well as in embryos in which the four quadrants still adhered to each other at the vegetal cross-furrow, the macromeres 3A-3D divided almost synchronously (Fig. 7). The maximal differences between the beginning of cleavage of the first and last dividing macromere were $3.6 \pm 2.2$ and 5.4 $\pm 4.9 \mathrm{~min}$, respectively.

\section{Division of the Macromeres after Deletion of the First Quartet Cells}

A. Deletion of the four micromeres 1a-1d (Fig. 11b). At the eight-cell stage the

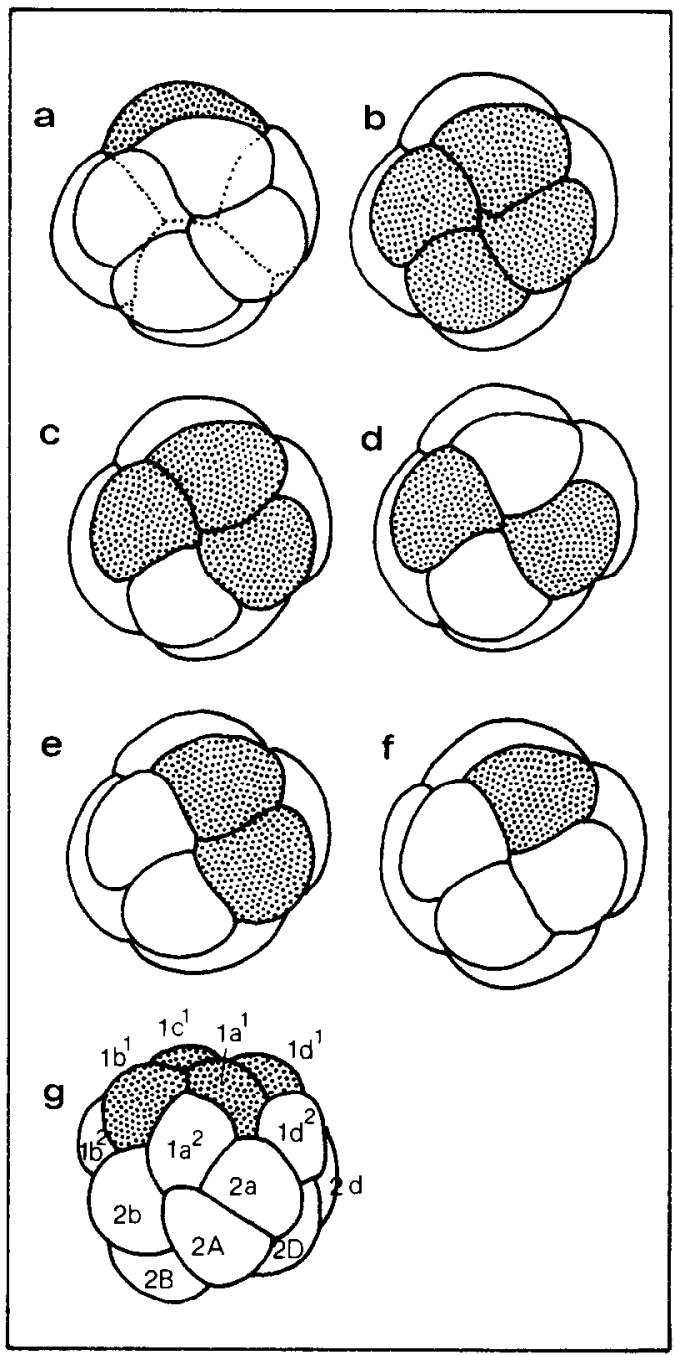

Fig. 11. Diagram of deleted blastomeres. The shaded cells have been deleted.

four animal cells $1 \mathrm{a}-1 \mathrm{~d}$ were removed. The division times of the macromeres at the formation of the fourth quartet of micromeres have been determined in 19 embryos. In comparison with the non-cross-furrow macromeres, the two cross-furrow macromeres divided with a significant delay of 4.0 min in 18 embryos (signed rank test, $P<$ 0.009). One embryo with an aberrant cleavage delay of $30 \mathrm{~min}$ in one of the two crossfurrow macromeres has been left out of consideration.

$B$. Deletion of three micromeres of the tier 1a-1d (Fig. 11c). This deletion was made in two embyros only. The maximal 
difference between the onset of the divisions of the macromeres was $3 \mathrm{~min}$.

C. Deletion of two opposite micromeres (Fig. 11d). In eight embryos two opposite micromeres were deleted at the eight-cell stage. If the cross-furrow macromere with the greatest division delay is arbitrarily denominated as $3 \mathrm{D}$, then this macromere has a division delay of $7.8 \mathrm{~min}$ in comparison with $3 \mathrm{~A}, 3 \mathrm{~B}$, and $3 \mathrm{C}$ (signed rank test, $P<$ 0.042 ).

D. Deletion of two adjacent micromeres (Fig. 11e). In 17 embryos two adjacent micromeres were removed at the eight-cell stage. In nine of these embryos the macromeres divided almost synchronously. The average difference between $3 \mathrm{~A} / 3 \mathrm{C}$ on the one hand and $3 \mathrm{~B} / 3 \mathrm{D}$ on the other was less than $1 \mathrm{~min}$ (signed rank test, $P<0.362$ ). In five of the remaining embryos one of the cross-furrow macromeres had a delay of 14 min on the average. In the other three embryos one of the non-cross-furrow macromeres had an average delay of $13 \mathrm{~min}$. This may indicate that after a one-sided delation the internal disposition of the macromeres may be changed in such a way that one of the lateral macromeres becomes more frequently determined as the stem cell of the primary mesentoblast.

$E$. Deletion of a cross-furrow micromere (Fig. 11f). In 20 embryos one of the micromeres 1a-1d was deleted. In all embryos except one, one of the cross-furrow macromeres was significantly delayed in comparison with the other macromeres that divided almost synchronously. The average delay is of the same order as in control embryos (15.2 min; signed rank test, $P=$ 0.000).

F. Deletion of $1 a^{1}-1 d^{1}$ (Fig. 11g). After the first division of the micromeres 1a-1d, the animal tier $1 a^{1}-1 d^{1}$ was eliminated in six embryos. The absence of these micromeres is accompanied with the absence of a differentiation of the macromeres, as the maximal observed difference between the first and last dividing macromere was only $4 \mathrm{~min}$.

\section{DISCUSSION}

During normal development one of the two cross-furrow macromeres forms the mesentoblast (4d or M). After deletion of one of these two macromeres, the remaining cross-furrow macromere or one of the two lateral macromeres demonstrate the characteristic behavior of a normal mesentoblast mother cell in most of the embryos (91.7\%). It attained the normal central position inside the embryo and divided unequally and with approximately the same division delay as during normal development. In ,embryos in which the differentiation between the macromeres failed to appear (two embryos, 8.3\%), none of the macromeres attained a central position, their division was synchronous, and a mesentoblast was not formed. These results affirm the assumption that the determination of one out of four equipotential macromeres to become the stem cell of the mesentoblast requires only that this macromere attains the exclusive central position in the center of the embryo.

The results of the micromere deletions demonstrate that the differentiation of the four macromeres, the formation of the primary mesentoblast, and the expression of bilateral symmetry and dorsoventral polarity require the presence of a minimal number of micromeres of the animal first quartet. The dissociation experiments also confirm that the exclusive contacts developed between one macromere and the micromeres of the animal first quartet in embryos of Lymnaea and Patella (van den Biggelaar, 1976a; 1977) are essential for the differentiation of that macromere into the stem cell of the mesentoblast. It may be assumed that the differential cell contacts induce a divergence in the chemodifferentiation of the blastomeres. This may be deduced from the development of Lymnaea stagnalis, in which all four macromeres contain concentrations of maternal RNA along the cell walls in the region of the vegetal cross-furrow. These so called ecto- 
somes (Raven, 1946, 1970, 1974; Minganti, 1950; van den Biggelaar, 1971) behave quite differently in the central 3D macromere as compared to the other macromeres. In $3 \mathrm{D}$ the ectosomal RNA is redispersed and can no longer be recognized some time after the transition from the radially symmetrical configuration of cells into the bilaterally symmetrical disposition. In the other macromeres, this ectosomal RNA becomes progressively concentrated and is probably extruded afterward into the cleavage cavity (van den Biggelaar, 1976b).

The gradual displacement of one of the four macromeres toward the center of the embryonic cell mass in the interval between the fifth and the sixth cleavage may be regarded as a decisive event. This displacement probably happens as soon as a critical number of cells is reached. It forces each of the other blastomeres to change its position in relation to that single central cell, and the initial radial symmetry is instantaneously lost. Any differentiation within the successive tiers of micromeres along the egg axis is based upon the topographical relations to the axial macromere. This is distinctly demonstrated in the division pattern of the third quartet cells. The micromeres to the right (3d) and to the left (3c) of the central macromere divide into smaller lower and larger upper cells, whereas the two micromeres of the opposite future ventral side (3a and $3 b$ ) divide into larger lower and smaller upper cells (Fig. 2). This leads to the conclusion that positional differences between blastomeres with comparable cytoplasmic compositions precede the divergence of their developmental pathways. The decisive morphogenetic significance of the configuration of the blastomeres is supported by the development of a normal embryo from a single blastomere of a twocell stage in Lymnaea palustris. In this species a normal embryo is obtained if an isolated blastomere divides as a normal egg, i.e., if the complete division program is repeated, and a normal cell configuration is attained. If the blastomeres divide still being part of the whole embryo and develop a four-cell stage with two micromeres and two macromeres, abnormal embryos are obtained (Morrill et al., 1973).

The possibility of an epigenetic determination of dorsoventral polarity has also been demonstrated in Limax maximus. In this gastropod the eggs develop normally, irrespective of the position of the first meridional cleavage plane (Guerrier, 1970a). No difference can be observed between the developmental potencies of the blastomeres isolated at the two-cell stage (Guerrier, 1970c).

In any model of blastomere determination via cellular interactions, it is clear that the cell membrane must play a key role in the control of differentiation. The present results demonstrate that cellular interaction is of crucial importance during the early development of the molluscan embryo, and that it is no longer tenable to rely exclusively upon preformed regional differences as assumed in the mosaic model. On the contrary, dynamic structures have to be introduced that can recognize contact signals. Translated in the competent cells these signals may be further active either in controlling nuclear functions or in regulating cellular mechanisms at a posttranscriptional or posttranslational level.

According to the above concepts it appears possible to interpret the determination of dorsoventral polarity in spiralian embryos, irrespective of whether they develop an equal or an unequal four-cell stage. In forms with an equal four-cell stage, all four macromeres contain vegetal structures and appear to be equipotential. In the interval between the fifth and sixth cleavage, these structures are activated in one macromere, and as a consequence, this macromere differentiates into the stem cell of the mesoderm. In forms with an unequal fourcell stage the vegetal structures are exclusively segregated into one of the macromeres via the fusion of a polar lobe or an unequal division. The vegetal determinants appear to have an important and definite 
morphogenetic value. Removal of the polar lobe at first cleavage leads to the formation of radially symmetrical embryos (Clement, 1952; van Dongen and Geilenkirchen, 1975; van Dongen, 1976; Wilson, 1904). Equal subdivision of the vegetal region between the first two blastomeres results in the production of double embryos (Guerrier, 1970; Guerrier et al., 1978).

Experiments by Clement on embryos of Ilyanassa have indicated that the polar lobe region, including most of the vegetal structures, does not immediately exert its influence. This is postponed to the interval between fifth and sixth cleavage. This is exactly the same interval as that in which dorsoventrality is determined in species with an equal first division. Therefore, it may also be expected that in spiralian embryos forming a polar lobe, the important vegetal structures must be activated during the cleavage cycle prior to the formation of the mesentoblast, via an interaction with the animal micromeres.

It may be concluded that in addition to the cytoplasmic composition of the blastomeres, the cell contacts, the biochemical mechanism causing specific cellular affinities, and the mechanisms by which such contacts may control the differentiation of the interacting cells must be investigated for a better understanding of early molluscan morphogenesis.

The first author wishes to thank Professor Dr. J. Bergerard for the hospitality at the Biological Station of Roscoff, and the Centre National de la Recherche Scientifique of France for financial support (A.T.P. internationale A 655-9102). Ir. J. J. Bezem is gratefully acknowledged for the statistical analysis of the results.

\section{REFERENCES}

Biggelaar, J. A. M. van den (1971). Timing of the phases of the cell cycle during the period of asynchronous division up to the 49-cell stage in Lymnaea. J. Embryol. Exp. Morphol. 26, 367-391.

BigGelaAR, J. A. M., vAN DEN (1976a). Development of dorsoventral polarity preceding the formation of the mesentoblast in Lymnaea stagnalis. Proc. Kan. Ned. Akad. Wetensch. Ser. C 79, 113-126.

BiggelaAR, J. A. M. VAN DEN (1976b). The fate of maternal RNA containing ectosomes in relation to the appearance of dorsoventrality in the pond snail, Lymnaea stagnalis. Proc. Kon. Ned. Akad. Wetensch. Ser. C 79, 421-426.

BiggelaAR, J. A. M. vaN DEN (1977). Development of dorsoventrality and mesentoblast determination in Patella vulgata. J. Morphol. 154, 157-186.

Clement, A. C. (1952). Experimental studies on germinal localization in Ilyanassa. I. The role of the polar lobe in determination of the cleavage pattern and its influence in later development. J. Exp. Zool. 121, 593-625.

Clement, A. C. (1962). Development of Ilyanassa following removal of the D-macromere at successive cleavage stages. J. Exp. Zool. 149, 193-216.

Dongen, C. A. M. van (1976). The development of Dentalium with special reference to the significance of the polar lobe. V. Differentiation of the cell pattern in lobeless embryos of Dentalium vulgare (Da Costa) during late larval development. Proc. Kon. Ned. Akad. Wetensch. Ser, C 79, 245-266.

Dongen, C. A. M. van, and Geilenkirchen, W. L. M. (1975). The development of Dentalium with special reference to the significance of the polar lobe. IV. Division chronology and development of the cell pattern in Dentalium dentale after removal of the polar lobe at first cleavage. Proc. Kon. Ned. Akad. Wetensch. Ser. C 78, 358-375.

Guerrier, P. (1970a). Les caractères de la segmentation et la détermination de la polarité dorsoventrale dans le développement de quelques Spiralia. I. Les formes a premier clivage égal. J. Embryol. Exp. Morphol. 23, 611-637.

Guerrier, P. (1970b). Les caractères de la segmentation et la détermination de la polarité dorsoventrale dans la développement de quelques Spiralia III. Pholas dactylus et Spisula subtruncata. J. Embryol. Exp. Morphol. 23, 667-692.

Guerrier, P. (1970c). Nouvelles données expérimentales sur la segmentation et l'organogenèse chez Limax maximus (Gastéropode pulmoné). Ann. Embryol. Morphol. 3, 283-294.

Guerrier, P., BiggelaAr, J. A. M. van Den, DonGEN, C. A. M. VAN, and Verdonk, N. H. (1978). Significance of the polar lobe for the determination of dorsoventral polarity in Dentalium vulgare (da Costa). Develop. Biol. 63, 233-242.

Krischner, K. N., and Chambers, E. L. (1970). Proteolytic enzymes in sea urchin eggs: Characterization, localization and activity before and after fertilization. J. Cell. Physiol. 76, 23-36.

Minganti, A. (1950). Acidi nucleici e fosfatasi nello sviluppo della Lymnaea. Riv. Bioi. 42, 295-319.

Morrill, J. B., Blair, C. A., and Larsen, W. J. (1973). Regulative development in the pulmonate gastropod Lymnaea palustris, as determined by deletion experiments. J. Exp. Zool. 183, 47-56.

Raven, Chr. P. (1946). The development of the egg of Lymnaea stagnalis L. from the first cleavage till 
VAN DEN BiggelaAR aNd GuerRier

the trochophore stage, with special reference to its "chemical embryology". Arch. Néerl. Zool. 7, 353-434.

RAVEN, Chr. P. (1970). The cortical and subcortical cytoplasm of the Lymnuea egg. Int. Rev. Cytol. 28, $1-44$.

RAven, Chr. P. (1974). Further observations on the

distribution of cytoplasmic substances among the cleavage cells in Lymnaea stagnalis. J. Embryol. Exp. Morphol. 31, 37-59.

WILson, E. B. (1904). Experimental studies on germinal localization. II. Experiments on the cleavagemosaic in Patella and Dentalium. J. Exp. Zool. 1, 197-268. 